\title{
Assessment of Bed Bathing Methods in the Faroe Islands
}

\author{
Lis Horstmann Nøddeskou ${ }^{1, ~}$, Naina Túgvustein ${ }^{2}$, Asta Marjunardóttir ${ }^{2}$, Ingun Gaardbo², \\ Lars Hemmingsen ${ }^{1}$, Britta Hørdam ${ }^{1}$
}

${ }^{1}$ Medicine Department, Zealand University Hospital, Køge, Denmark

${ }^{2}$ National Hospital, Tórshavn, Faroe Islands

Email address:

1hn@regionsjaelland.dk(L. H. Nøddeskou)

${ }^{*}$ Corresponding author

\section{To cite this article:}

Lis Horstmann Nøddeskou, Naina Túgvustein, Asta Marjunardóttir, Ingun Gaardbo, Lars Hemmingsen, Britta Hørdam. Assessment of Bed Bathing Methods in the Faroe Islands. American Journal of Nursing Science. Vol. 7, No. 3, 2018, pp. 109-114.

doi: 10.11648/j.ajns.20180703.15

Received: April 21, 2018; Accepted: May15, 2018; Published: June 1, 2018

\begin{abstract}
There are two types of bed baths: the traditional basin used with soap and water, and the disposable bath, which is pre-packed in single-use units and heated before use. From earlier studies it was recommended with further studies witch would strengthen the evidence. To compare the traditional basin bed bath to a disposable bed bath, there are three factors that need to bed considered: (1) duration and quality of the bath, (2) patient satisfaction and (3) nurse satisfaction.31 patients received bed baths on two consecutive days. The patients were bathed by the same nurse on both days. The bed baths were observed in relation to duration and quality. Nurses and patients were interviewed about their preferences. The study was performed in both surgical and medical floors. Both types of bed baths scored very highly in the area of quality. Significantly less time was used with the disposable bed baths $(\mathrm{p}<0.001)$. The registered nurses prefer the disposable bath $(78 \%)$. The patients were satisfied with both types of bed baths. There was no significant difference in the results. Even when we adapt the results in relation to the patients' gender and age, there is still no significant difference. Patients rated the bed baths equally in most cases. By this study we applied further research in the area of personal hygiene. When all aspects of bed baths are considered (time, cost, quality, and patient and nurse preferences), both types of bed baths are secure and well received. Due to the times savings achieved and the importance of this for patients (who are weak and need nursing assistance to perform personal hygiene), we recommend the use of disposable bed baths.
\end{abstract}

Keywords: Bed Bath, Bag Bath, Disposable Baths, Bathing, Hygiene, Washing with Out Water, Patient Involvement, Satisfaction

\section{Introduction}

\subsection{Background}

With the aim of strengthening evidence within the field of nursing and promoting experience in research projects, a collaborative partnership has been established between the Danish research group into bed baths at the Zealand University Hospital in Køge and the Nursing Management team at the National Hospital, Landssjúkrahúsið in Tórshavn, in the Faroe Islands.

Since the disposable bath was invented in 1994, there have been a number of research efforts into the product, which have been published [1-17]. The research comes from a number of countries UK, US, Nederland and Denmark. All knowledge gained from these studies has been included in the development of this project to ensure that the knowledge is not wasted, but further developed and strengthened.

A steering committee was established with representation from the Faroe Islands and Denmark. A Danish delegation went to the Faroe Islands to introduce the project and to teach 32 Faroese nurses how to collect and handle data correctly. The bed bathing method was reviewed in detail to ensure there were no problems in collecting qualified data [9].

It was decided that there was sufficient basis for carrying out the study.

The previously prepared protocol was established [8]. Applications for financial support were sent and measures 
put in place to ensure the project could be implemented within the economic framework. The project was completed during the period 1 April 2014 to 31 December 2015.

\subsection{Aim}

The aim was to compare a disposable bed bath (consisting of eight microwavable pre-fabricated washcloths with cleanser) with a traditional bed bath (wash basin, soap, cloths and towels) using a variety of parameters.

To evidence base new technology (bath method) to secure the patients gets qualified and good nursing.

The third objective was for nurses at Landssjúkrahúsið in Torshavn to develop and implement research methodology, knowledge and experience in research projects.

\section{Method}

\subsection{Design}

The project is a replication study because the method used in the Danish project could be reused (8). The method is a mixed method, which included observations and questions to patients and nurses. In addition, there was a crossover to ensure all the participants tried both types of bed bath. The questionnaires were available in Danish and Faroese, so that all the participants were fully aware of the project's purpose and implementation. The patients were from both medical and surgical floors and more than 18 years.

A cost comparison of the two types of bed baths was not repeated as all previous studies had already shown that using disposable bed baths to bathe patients was significantly cheaper $[3,5,8]$. The type of bed bath used on day 1 was drawn at random to avoid biased responses.

Data was collected over two consecutive days and kept confidential until the entire project period was completed.

The project was performed by two nurses: one carrying out patient bathing and one observer. The observer recorded time and accurately entered the data in minute numbers. All procedures were quality checked to ensure high quality was maintained when carrying out patient bathing using the two types of bed bath.

There were eight quality checkpoints:

1. Gathering the necessary equipment before beginning the bath

2. Wearing gloves

3. Explaining procedures to the patient

4. Checking the patient's wellbeing throughout the duration of the bath

5. Ensuring the patient's privacy is protected
6. Avoiding recontamination of skin surfaces

7. Cleaning all body surfaces (e.g. axilla, groin, feet)

8. Disposing of waste and equipment without environmental contamination

For statistical purposes, the Statistical Package for the Social Sciences (SPSS) version 17 was used [18]. All statistics were carried out using non-parametric statistical tests. Non-pared statistics were made using the MannWhitney test, and pared statistics were made using the Wilcoxon signed-rank test $[19,20]$.

\subsection{Ethical Considerations}

Ethical approval was obtained from the Vísindasiðsemisnevndin (Research Ethics Council of the Faroe Islands) and registered at the Dátueftirlitið (Data Committee) (ID number: skjalasavnið 2014-07). In accordance with the Declaration of Helsinki, participants gave written consent after having received written and verbal information about the study, including: the purpose and procedures, the voluntary nature of participation and the option to withdraw at any time.

Participants were guaranteed confidentiality and secure data storage. Other ethical considerations were respected in relation to being observed while receiving assistance with personal hygiene. Since the observers were nurses, they were trained to be discrete and to respect a patient's modesty.

\section{Results}

\subsection{Data}

Data collection took place in 2014-2016. After almost two years, when the participation rate was up to 31 patients compared to the estimated 50 , the project was finalized.

Table 1. The dataset consisted of 31 patient subjects, of which two died on the second day.

\begin{tabular}{lll}
\hline & Number & Age (years) Mean (interval) \\
\hline Female & 17 & $74(62-94)$ \\
Male & 14 & $71(52-89)$ \\
\hline
\end{tabular}

The women marginally outnumbered the men. The mean age for the women (74 years) is slightly higher than that of the men (71 years), while the spread is slightly greater for the men (37 years) compared to the women (32 years). However, the differences are not significant. This shows that we have a representative group of patients admitted to hospitals medical and surgical beds.

Table 2. Time consumption for the two types of bed bath.

\begin{tabular}{llll}
\hline & $\begin{array}{l}\text { Disposable bed bath Mean (interval) } \\
\text { Minutes }\end{array}$ & $\begin{array}{l}\text { Traditional bed bath Mean (interval) } \\
\text { Minutes }\end{array}$ & Significance test Rank test (p-value) \\
\hline Preparation & $2.8(1-5)$ & $3.4(2-6)$ & 0.018 \\
Bed bath & $11.8(6-23)$ & $14.8(4-29)$ & 0.000 \\
Cleanup & $2.3(1-4)$ & $3.3(1-10)$ & 0.001 \\
Total & $16.9(10-29)$ & $21.6(9-41)$ & 0.000 \\
\hline
\end{tabular}


There is a significant difference in time consumption across all parameters. The most significant is the time spent on performing the bed bath itself, which impacts the total time consumption. Therefore it is clear that using the disposable bed bath is quicker compared to using the traditional bed bath. The result reinforces the significance of previous studies.

Table 3. Quality checkpoints met for the two types of bed bath.

\begin{tabular}{lll}
\hline Number of checkpoints met & Disposable bed bath Number (\%) & Traditional bed bath Number (\%) \\
\hline 5 & & $1(3 \%)$ \\
6 & $5(17 \%)$ & $3(10 \%)$ \\
7 & $25(83 \%)$ & $27(87 \%)$ \\
8 & 30 & 31 \\
\hline
\end{tabular}

There was no significant difference in the perception of quality of the two types of bed baths, with regard to the eight quality checkpoints. A high target was achieved in both bathing methods $(>80 \%)$. This was also the goal of the project, to ensure a true comparison of the two types of bed baths. Important, when you invent a new technology to be sure, that the quality of the procedure keeps up with good standard of nursing. The quality checkpoints are meet here.

Table 4. Patients' overall assessment of the two types of bed bath.

\begin{tabular}{|c|c|c|c|c|}
\hline & \multirow{2}{*}{$\begin{array}{l}\text { Disposable bed bath } \\
\text { Mean (interval) }\end{array}$} & \multirow{2}{*}{$\begin{array}{l}\text { Traditional bed bath } \\
\text { Mean (interval) }\end{array}$} & \multicolumn{2}{|l|}{ Comments } \\
\hline & & & Highest score & Lowest score \\
\hline How nice was it to be bathed today? (interval 1-5) & $1.8(1-3)$ & $1.7 *(1-3)$ & Very nice: 1 & Terrible: 5 \\
\hline How clean do you feel after the bath? (interval 1-5) & $1.8(1-3)$ & $1.7 *(1-5)$ & Very clean: 1 & Not clean at all: 5 \\
\hline How was the duration of the bath? (interval 5-1) & $4.7(1-5)$ & $4.6 *(1-5)$ & Sufficient: 5 & Too quick or too long: 1 \\
\hline
\end{tabular}

*No significant difference.

As seen from the table 4, there was no significant difference between the patients' perception of the two types of bed baths. All patients in the Faroe Islands were satisfied with the bed baths, regardless of the method used. When we process the data in relation to gender and age, there is still no significant difference

Table 5. Patients' preferences by gender and age.

\begin{tabular}{lll}
\hline Patients Gender & Disposable bed bath Percent (number) & Traditional bed bath Percent (number) \\
\hline Female & $35 \%(6)$ & $65 \%(11)$ \\
Male & $42 \%(5)$ & $58 \%(7)$ \\
\hline & & \\
\hline Patients Age & Disposable bed bath Percent (number) & Traditional bed bath Percent (number) \\
\hline$<=70$ years & $21 \%(3)$ & $79 \%(11)$ \\
$>70$ years & $53 \%(8)$ & $47 \%(7)$ \\
\hline
\end{tabular}

*No significant difference.

Our test of different preference between age and gender is shown in table 5. It seems, that all patients have the same evaluation, which leads us to be able to use the disposable baths as well as the traditional bath no matter of patient gender or age.

Table 6. Nurses' assessment of the two types of bed bath.

\begin{tabular}{|c|c|c|c|c|}
\hline & Disposable bed bath & Traditional bed bath & Comments & \\
\hline & Score Mean (interval) & Score Mean (interval) & Lowest score & Highest score \\
\hline $\begin{array}{l}\text { When you think about the use of wipes, towels and wash } \\
\text { basins in relation to the bathing sequence how easy/nice was } \\
\text { it? }\end{array}$ & $7.4(3-10)$ & $7.2(3-10)$ & Not nice: 1 & Very nice: 10 \\
\hline
\end{tabular}

*No significant difference.

The nurses` assessment of the two types of bed bath showed no significant differences in relation to how easy/nice the bathing sequence was. 
Table 7. The individual nurses preferences.

\begin{tabular}{llll}
\hline \multirow{2}{*}{ Nurses scores } & Low score (3-6) & High score (7-10) & Fisher's test \\
\cline { 2 - 4 } & Number (\%) & Number (\%) & P-value \\
\hline Traditional bed bath & $7(41 \%)$ & $10(59 \%)$ & 0.04 \\
Disposable bed bath & $1(6 \%)$ & $15(94 \%)$ & Significant difference \\
\hline
\end{tabular}

According to the individual nurses preferences, the disposable bed bath scores significantly higher (94\%) compared to the traditional bed bath $(59 \%)$

Table 8. Which bathing method would you choose in future.

\begin{tabular}{llll}
\hline & Choosed bathing method (n) & Fisher's test & Comments \\
\cline { 2 - 3 } & $\mathbf{n} / \mathbf{N}(\%)$ & P-value & Significant difference \\
\hline Disposable bed bath & $11 / 14(78 \%)$ & 0.05 & \\
Traditional bed bath & $5 / 12(42 \%)$ & & \\
\hline
\end{tabular}

Nurses would in the future choose disposable bed baths (78\%) compared with traditional bed baths (42\%)。

Table 9. Comparison of patient and staff preferences.

\begin{tabular}{llll}
\hline \multirow{2}{*}{ Staff } & Patients & Disposable bed bath & Traditional bed bath \\
\cline { 2 - 4 } & & Percent (number) & Total \\
\hline Disposable bed bath & Percent (number) & $25 \%(7)$ & $32 \%(9)$ \\
Traditional bed bath & Percent (number) & $14 \%(4)$ & $29 \%(8)$ \\
Total & Percent (number) & $39 \%(11)$ & $61 \%(17)^{*}$ \\
\hline
\end{tabular}

*No significance.

Patients tend to prefer the traditional bed bath $(61 \%)$, while staff prefers the disposable bed bath (57\%).

\subsection{Analysis}

31 patients from surgical and medical floor fulfilled the two days study. The study replicated some of the earlier studies important areas.

We would have preferred more patients in this study. Some patients dropped out due to the fact of written consent. A lack of resources in the nursing floors meant that project work could not take place during weekends and holiday periods, which automatically excluded some patients from participation.

The time consumption (table 2) is important for weak patients. Their personal hygiene should be performed professionally and in order not to exhaust them. They need to have energy to eat, mobilize, other treatment and enjoy visitors too.

Due to introduction of new technology it is important to test and retest the methods, so patients can be treated with respect and in an ethical setting.

The nurses (table 6, 7 and 8) evaluated both types of bath, and they found them easy to perform but preferred the disposable bath. When they were asked, in the particular patient related situation, their preferences were the same, they would choose disposable bath the next time. We didn't ask why directly, but combined it with the answers that it was easy to use. Compared to other studies, nurses are overall satisfied with the disposable bed baths $[5,8]$.

When we compared both nurses and patients' preferences, there is a tendency, they do not totally agree. None of the results are significant in this study. We think, that patient involvement are important here, and the nurses should be aware of giving the patients information about the two bath types, so they are more capable of making their own choice. In other studies it is shown, that the older inhabitants gets more help with their personal hygiene where disposable bath are preferred in patients homes and in nursing homes $[9,10]$.

The engagement and participation of nurses and department leaders is also worth looking at. The results that were collected at the end of the project show that only 13 of the 32 nurses who were initially included and taught actually participated in the project and performed the tasks. Staff anonymity may have been another reason for nonparticipation. The anonymization of staff involved each of the participating nurses getting a number. When the nurses collected the data, they were requested to seal it in a closed envelope with their number on it. The low level of participation by staff may have had an impact on data collection, because the fewer participants there are, the higher the impact of the individual participant's assessment on the overall result.

\section{Discussion}

The biggest takeaway for Landssjúkrahúsið in connection with the project has been in relation to the process. One factor that is particularly important to project implementation, as we learned through this experience, is staff motivation and project ownership. For example, in future projects, there should be one project coordinator for the entire project, who facilitates the tasks amongst the various departments and serves as contact person for the participants -patients and staff. This role could also serve as a benchmark for the steering committee and the working group, as the role of each is also vital to the project's success. Someone also 
needs to take care of the day-to-day management of the project, to keep an overview, follow up on activities and ensure that the project is on track.

Other examples of things that could be done differently in future include reducing the number of employees who need to collect data and participate in the first round of teaching. Two to three people from each department might be enough and would more likely create a greater sense of ownership.

It became apparent that staff found participating in the project a challenge, especially because it was imperative to get patients to participate. There were surprisingly few patients who met the criteria for participation because a number of bedridden patients were not well enough to answer the questions. The study therefore never became a natural part of the daily bathing routine in any of the departments.

In addition, it is important from the outset to inform and explain to staff about Landssjúkrahúsið's expectations from them in relation to the project. Information should be communicated about what the final result would be used for so that each employee understands why he or she are carrying out the project and its importance to the department in the future. It is important that the project's purpose is communicated clearly to all parties from the start. This might motivate patients and staff to participate and increase participation.

Participation in the project has opened up the opportunity to include research into the day-to-day lives of nurses at Landssjúkrahúsið, and it may influence the approach of a group that is perhaps not that used to participating in or conducting research. The project has initiated a discussion about the possibility of initiating new studies at Landssjúkrahúsio, even to the extent that a project department could be created at the hospital.

Even if this project does not lead to other research projects, research and quality improvement projects in the field of nursing have been put on the agenda and can influence the staff's mind-set when talking about clinical research and quality improvement of practice. A change in mind-set can influence more nurses to carry out more studies as part of the work. A change in mind-set also means there is more reflection, with nurses becoming more analytical; leading to a positive influence on nursing becoming increasingly evidence-based.

\section{Conclusion}

The project shows that there is no difference in the preference of the two types of bed bath. If the two nurses, who bathed five and eight patients respectively, are excluded from the results - as per other research projects - it is clear that patients and nurses prefer the disposable bed bath. As in previous studies, this study also shows that there is a significant difference in time consumption regarding the two types of bed bath. This is significant in relation to how much effort the patient can manage, as well as the time it potentially frees up for other patient/nurse activities (e.g. mobilization, assistance at mealtimes, conversation, and other care tasks).

The quality of both bathing methods was satisfactory in relation to the observed checkpoints.

When all aspects of bed baths are considered (time, cost, quality, and patient and nurse preferences), both types of bed baths are secure and well received. Due to the time savings achieved and the importance of this for patients (who are weak and need nursing assistance to perform personal hygiene), we recommend the use of disposable bed baths.

Further studies about bed bathing methods in hospitals are recommended and a systematic review for hospital admitted patients hygiene is especially needed.

Thirteen nurses at the main hospital in the Faroe Islands (Landssjúkrahúsið) gained insights into how a research project is planned and implemented.

\section{References}

[1] Skewes SM. No more bed baths!... bag bath... a technique that lessens the risk of skin impairment. RN 1994; 57 (1):34-35.

[2] Carruth AK, Ricks D, Pullen P. Bag baths: an alternative to the bed bath. Nursing Management 1995 09; 26 (9):75.

[3] Collins F, Hampton S. Product focus. The cost-effective use of BagBath: a new concept in patient hygiene. Br J Nurs 2003 09/11; 12 (16):984.

[4] Greaves A. We'll just freshen you up, dear... a bed bath can often leave the patient dirtier. Nursing Times 1985 03/06; 81 (10):3.

[5] Larson EL, Ciliberti T, Chantler C, Abraham J, Lazaro EM, Venturanza M, et al. Comparison of traditional and disposable bed baths in critically ill patients. Am J Crit Care 2004 05; 13 (3): $235-241$.

[6] Lentz J. Daily baths: torment or comfort at end of life? J HOSP PALLIAT NURS 2003 Januar; 5 (1):34-39.

[7] Sheppard CM, Brenner PS. The effects of bathing and skin care practices on skin quality and satisfaction with an innovative product. J Gerontol Nurs 2000 10; 26 (10):36.

[8] Nøddeskou, Lis Horstmann; Hemmingsen, Lars E.; Hørdam, Britta; An Assessment of Traditional Bed Baths and Pre-packed Single Unit Baths - a Randomized Controlled Trial Scandinavian Journal of Caring Sciences, Jun2015; 29 (2): 347-352.

[9] van Achterberg T, van Gaal BGI, Geense WW, Verbeke G, van der Vleuten C, Schoonhoven L. Completeness of assisted bathing in nursing homes related to dementia and bathing method: results from a secondary analysis of clusterrandomised trial data. Int J Older People Nurs. 2015.

[10] Groven et al. How does washing without water perform compared to the traditional bed bath: a Systematic review. BMC Geriatrics (2017) 17:31

[11] Lawler J. Bak skjermbrettene: sykepleie, somologi og kroppslige problemer. Oslo: Gyldendal; 2002.

[12] Johnson D, Lineweaver L, Maze LM. Patient's bath basins as potential sources of infection: a multicenter sampling study. Am J Crit Care 2009; 18 (1):31-38. 
[13] Simmons SF. Resident Characteristics Related to the Lack of Morning Care Provision in Long-term Care. Gerontologist, The 2013; 53 (1):151.

[14] Nøddeskou LH, Hemmingsen LE, Hørdam B. Evidensbaseret sygepleje- et ledelsesansvar. Tidsskrift for kvalitet i Sundhedsvæsenet. Årgang 90 no 4. 2014

[15] Hørdam B, Brandsen RV, Frandsen TK, Bind A, Stuhaug HN, Petersen K. Nurse-assisted personal hygiene to older adults $65+$ in home care setting. J of Nursing Education and Practice. Oct 2017

[16] Schoonhoven L, Gall BGI, Teerenstra S, Adang E, Vleuten C, Achterberg T. Cost-consequence analysis og "washing without water" for nursing home residents: A cluster randomized trial. International J of Nursing Studies. 2014

[17] Gillis K, Tency I, Roelant E, Laureys S, Devriendt H, Lips D. Skin hydration in nursing home residents using disposable bed baths. Geriatr Nurs 2016 May-Jun; 37 (3):175-179.

[18] Nielsen T, Kreiner S. SPSS (Statistical Package for the Social Sciences). 3rd ed. Copenhagen: Jurist og Økonomforbundet; 2008.

[19] Lund H, Røgind H. Statistik i ord. 1. ed. Kbh: Munksgaard Denmark; 2004.

[20] Alban A. Sundhedsøkonomi - principper og perspektiver. 3. ed. Kbh: DSI - Institut for Sundhedsvæsen; 2006. 